\title{
Assentamentos urbanos e autoconstrução: inserção na cidade saudável
}

Dossier de Pesquisa : CidAde SAUdÁvel

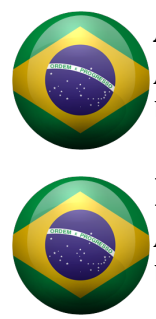

\section{Adriana Aparecida Carneiro Rosa}

Arquiteta e Urbanista, Centro Universitário de Jaguariúna, e Faculdade de Engenharia Civil, Arquitetura e Urbanismo - Unicamp. Campinas [SP] Brasil <dricarneiro@hotmail.com>.

\section{Evandra Ramos Victorio}

Arquiteta e Urbanista, Centro Universitário de Jaguariúna, e Faculdade de Engenharia Civil, Arquitetura e Urbanismo - Unicamp. Campinas [SP] Brasil <evandra@robertoleme.com>.

\begin{abstract}
Resumo
A acelerada urbanização nos grandes centros muitas vezes não segue diretrizes ideais de crescimento, provocando sérios problemas de degradação ambiental e grandes prejuízos na qualidade de vida da população. Para compreender o espaço urbano dentro da relação dos assentamentos irregulares e da autoconstrução das grandes cidades, precisa estar atento a inúmeros quesitos, dentre eles, o surgimento de favelas que representa falha do poder público. Nas primeiras consequências da ocupação do espaço, percebe-se que devido a acelerada urbanização, cidades sofrem influência de todo complexo da estrutura urbana, principalmente em áreas mais precárias. Contudo, em respeito ao cotidiano das comunidades, bem como a valorização do ponto de vista dos moradores e ativos das favelas, olhares para esses lugares não deveriam vir como um problema, mas sobretudo como um desafio. Acredita-se que o estabelecimento de princípios de desenho urbano que levem em conta "o enxergar" esses moradores como protagonistas, onde existe sim o problema das habitações precárias, entretanto pode-se enfrentar esse repto e então propor soluções para locais bem consolidados, em busca da qualidade de vida, onde o legado é muito maior. Como proposta de intervenção interdisciplinar, esses espaços urbanos podem reduzir o impacto nas áreas mais vulneráveis e, consequentemente, transformar a infraestrutura melhorando o ambiente de forma geral na inserção da cidade saudável.
\end{abstract}

\section{Palavras-chave}

Assentamentos Urbanos. Autoconstrução. Cidade Saudável.

\section{Urban settings and self-construction: inserting in the healthy city}

\begin{abstract}
The accelerated urbanization in large centers often does not follow ideal growth guidelines, causing serious problems of environmental degradation and great losses in the quality of life of the population. To understand the urban space within the relationship of irregular settlements and self-construction of large cities, you need to be aware of numerous issues, among them, the emergence of favelas that represent a failure of public power. In the first consequences of the occupation of space, one can perceive that due to accelerated urbanization, cities are influenced by every complex of urban structure, especially in more precarious areas. However, in regards to the daily life of the communities, as well as the appreciation of the residents 'and slums' points of view, looks at these places should not come as a problem, but especially as a challenge. It is believed that the establishment of urban design principles that take into account "seeing" these residents as protagonists, where there is rather the problem of precarious housing, however one can face this challenge and then propose solutions to well-established places, in quality of life, where the legacy is much greater. As a proposal for interdisciplinary intervention, these urban spaces can reduce the impact on the most vulnerable areas and, consequently, transform the infrastructure improving the environment in general in the insertion of the healthy city.
\end{abstract}

\section{Keywords}

Urban Settlements. Self-construction. Healthy City. 


\section{Introdução}

Inúmeros estudos realizados no mundo todo têm contribuído para propor ferramentas importantes para diminuir o déficit habitacional global. Este artigo aborda uma síntese bibliográfica em contrapartida com os apontamentos de propostas interdisciplinares, de diferentes aspectos sobre a forma de como os assentamentos urbanos e a autoconstrução estão inseridos no contexto dos estudos sobre o ambiente construído. A forma como as pessoas vivem e as escolhas que fazem estão relacionadas ao contexto e cultura do espaço de sua cidade, aos hábitos adquiridos nos ambientes familiares e sociais e ao conhecimento que lhes é disponibilizado (Moysés, Krempel, \& Moysés, 2010). É feito uma abordagem sobre a construção e surgimento desses espaços, e também é tratada a aplicabilidade do direito ao projeto, cujo o foco está na população de baixa renda, tendo em vista que a assistência técnica pode mudar a face das cidades brasileiras. Dentro do estudo do espaço urbano e da sua articulação com outras áreas, está salientada a composição dos assentamentos urbanos no entorno da cidade, do mesmo modo que a questão da verticalização dessa autoconstrução e da possível relação com espaços públicos.

Em dezembro de 2008, foi promulgada a Lei Federal no 11.888 (BRASIL, 2008), que estabelece o direito à assistência técnica pública e gratuita para famílias de renda com até 3 salários mínimos, desde que esteja localizada em área de interesse social, podendo construir, ampliar, ou ainda regularizar (fundiária) casas de até $60 \mathrm{~m}^{2}$, para o projeto e a construção de habitação de interesse social.

Com a ideia de ampliar o alcance da arquitetura e urbanismo no Brasil, recomenda-se que os estados de governo, ao conhecerem a Lei Federal no 11.888, de 24 de dezembro de 2008, a qual trata especificamente da Assistência Técnica em Habitação de Interesse Social - ATHIS, avaliem e regulamentem essa lei, de modo que construa ferramentas importantes para diminuir o déficit habitacional brasileiro, e ainda, que possam ser incorporadas no processo de ordenamento do território. Os Conselhos de Arquitetura e Urbanismo - CAU/BR e CAU/DF publicam, em seus sites regularmente, iniciativas bem sucedidas na área, a fim de divulgar as boas ideias desenvolvidas em todo o país.

Sabe-se que a acelerada urbanização nos grandes centros, que muitas vezes não segue diretrizes ideais de crescimento direcionado, acaba por provocar sérios problemas de degradação ambiental, bem como grandes prejuízos na qualidade de vida da população em geral (Rosa, 2017).

A precariedade dos espaços e do conforto ambiental nos assentamentos urbanos em geral está diretamente ligada a falta de orientações técnicas, precariedade essa, oriunda do baixo nível de conhecimento dos autoconstrutores. Por esse motivo, torna-se importante a atuação do poder público do governo local, bem como de parcerias institucionais direcionadas a trabalhar questões iniciais da autoconstrução, como forma de contribuir para melhorar a qualidade de vida da população que vive em assentamentos urbanos. Para atingir o nível de qualidade desejado, uma vez que existem restrições na forma de construção e ao acesso dos materiais de qualidade, é importante a concepção de um projeto como ferramenta fundamental. A metodologia do projeto de arquitetura deve privilegiar os critérios e indicadores funcionais, espaciais e de conforto buscando a qualidade e a satisfação do usuário das edificações (Pina, 2002).

Para que a ação transformadora do meio físico seja corretamente desenvolvida, fazem-se necessárias a organização e a instrumentalização das informações sobre os elementos físico-ambientais. Deve-se destacar, ao mesmo tempo, que aquelas construções e traçados urbanos primitivos que constituem constantes exemplos de "boa" arquitetura não são mais de que realizações que evidenciam em profundo conhecimento do lugar do futuro assentamento a fim de obter uma adequada adaptação a ele. Evidenciam também uma utilização dos materiais e das técnicas construtivas locais (Romero, 2000).

Uma experiência em sala de aula também pode ser compartilhada de modo que contribua para troca de conhecimentos no que diz respeito aos estudos de assentamentos e propostas de melhorias projetuais. Através de estudos e pesquisa em algumas referências sobre Habitação de Interesse Social - HIS houve uma proposta interdisciplinar de trabalhar com alunos do curso de arquitetura e urbanismo. 
A importância de abordar dentro das disciplinas de projeto, dos cursos de graduação em arquitetura e urbanismo, os aspectos sobre uma reflexão a respeito da habitação coletiva na sociedade contemporânea, bem como a elaboração de projeto arquitetônico de habitação multifamiliar, torna-se recorrente nos dias atuais. Tendo em vista a necessidade de escolha do local de estudo, a priori surge a ideia de uma vista técnica do corpo docente, acompanhado pelos alunos da disciplina de projeto, para uma possível análise local e interação com a comunidade protagonista da área em questão.

Acredita-se que diferentes tipologias de projeto que levem em conta o processo de autoconstrução, possam agregar valores, e que, projetos-padrão usados nos grandes conjuntos habitacionais de Campinas são inadequados principalmente no calor, e que eles podem ser melhorados com modificações razoavelmente simples e econômicas (Labaki \& Kowaltowski, 1995). A sistematização e elaboração de informações traduzidas numa prática constante aos planejadores e arquitetos, contribui tangencialmente para a construção de espaços habitáveis às atividades do homem do ponto de vista de sua adequação térmica e salubridade ambiental. E como os grandes avanços tecnológicos e as mudanças globais, sociais e econômicas que ocorreram nas últimas décadas influenciam diretamente os trabalhos realizados na área da autoconstrução, faz-se necessário a implementação de reformas diretivas a população dos assentamentos urbanos, em busca de melhorias sociais e do conforto ambiental às moradias autoconstruídas.

Os assentamentos urbanos nas cidades em crescimento estão adotando um estilo específico de construção que pode ser encontrado aspectos da arquitetura vernacular. Estes assentamentos e suas casas individuais, no entanto, têm vários aspectos negativos que devem ser analisados e corrigidos (Labaki \& Kowaltowski, 1998).

Partindo do pressuposto de que deve-se entender que a cidade também é um objeto arquitetônico, pois é um espaço construído e como tal, sua concepção é apreendida pela percepção visual. 0 desenvolvimento das cidades e da civilização foi significativamente influenciado pelas dificuldades encontradas nos lugares onde as comunidades se localizavam (Saldiva, 2018).

A configuração da cidade ocorre pela presença dos espaços públicos, isto é, locais definidos para o usufruto de todo e qualquer membro da sociedade, sendo locais referenciais e de encontro entre as pessoas. Da mesma forma, os assentamentos urbanos também compartilham desses espaços, lugares onde a comunidade se reúne para a integração social, seja ela momentânea ou permanente, e que sensitivamente, procuram pontos embaixo de árvores, cuja sensação de conforto é mais agradável. E com ações de mitigação, esses espaços urbanos podem reduzir o impacto ambiental nas áreas mais vulneráveis e, consequentemente, transformar a infraestrutura melhorando o ambiente de forma geral.

\section{Objetivo}

Avaliar a forma de viver nos assentamentos urbanos, dentro de uma escala acadêmica, bem como buscar construir melhores condições de vida na cidade, é de suma importância para os pesquisadores colocarem no centro de suas preocupações técnico-científicas os tão graves problemas sociais e de más inserções do espaço urbano, tornando a autoconstrução mais assistida aos olhares técnicos.

\section{Método}

\subsection{Revisão da literatura e projeto interdisciplinar}

O estudo de revisão da literatura desenvolveu para avaliar algumas pesquisas sobre a compreensão dos assentamentos urbanos e da autoconstrução no espaço urbano e as formas de melhorias através da assistência técnica aos moradores dos assentamentos no entorno, enquanto cidade. Avaliou também os aspectos da autoconstrução no meio urbano, onde muitas vezes não existem diretrizes ideais de crescimento, o que ocasiona muitos problemas de degradação ao meio ambiente, no contexto da infraestrutura urbana e causa sérios prejuízos na qualidade de vida da população em geral. E ainda propõe uma análise acadêmica sobre a condição urbana, a forma como os assentamentos urbanos se apropriam do espaço, a possível intervenção técnica assistida de projeto e a 
marca do empreendedorismo e da superação de obstáculos dos moradores de favelas na busca pela qualidade de vida mais adequada à comunidade.

\subsubsection{Atuação do desenho urbano e as propostas de projeto}

Como proposta de intervenção de uma área irregular da cidade de Campinas, SP, conforme Figura 1, o curso de arquitetura e urbanismo, do Centro Universitário de Jaguariúna traz na disciplina de Projeto IV, referente ao $5^{\circ}$ semestre, dentro de seu cronograma 3 módulos, sendo eles: análise de referências e levantamento de dados, proposta de reformulação urbana e ocupação do solo, e ainda, projeto de habitação multidisciplinar - uso misto HCSE, cujo desenvolvimento ocorreu durante o $1^{\circ}$ semestre de 2018.

Nas grandes cidades e regiões metropolitanas, por exemplo, observa-se com frequência cada vez mais assentamentos urbanos irregulares. Tendo em vista a expansão das cidades, sem qualquer limitação do território, pode-se relacionar este fato ao crescimento desordenado da população, o qual vem provocando um grande impacto das atividades humanas sobre o meio ambiente. As alterações previstas no clima global devem impactar fortemente os assentamentos humanos, sobretudo os urbanos (Braga, 2012). 0 maior problema do Brasil não é a pobreza, mas a desigualdade e a injustiça a ela associadas. Desigualdade econômica e desigualdade de poder político (Villaça, 2012).

\subsubsection{Espaço urbano e a modernidade}

No módulo 1, em forma de seminário, os alunos apresentam seus primeiros estudos referenciais e levantamento dos dados, elaborando propostas de projeto e críticas a serem referenciadas e utilizadas como base para seus projetos. Em segunda instância, no módulo 2 ocorre o desenvolvimento das concepções de projeto trabalhadas numa macro escala, de acordo com Figura 1, onde todos os estudos acontecem de forma interdisciplinar, envolvendo além do projeto arquitetônico, paisagismo e infraestrutura urbana. E a terceira parte do estudo da disciplina, no módulo 3 desenvolvem projetos apresentados em forma de estudo preliminar, com seus eixos definidores e imagens tridimensionais, contendo: implantação geral da área, destacando a(s) quadra(s) do projeto da HIS, implantação dos projetos na quadra(s), planta do pavimento tipo e 2 cortes, planta com layout (escala ampliada) com cotas internas e memorial de área.

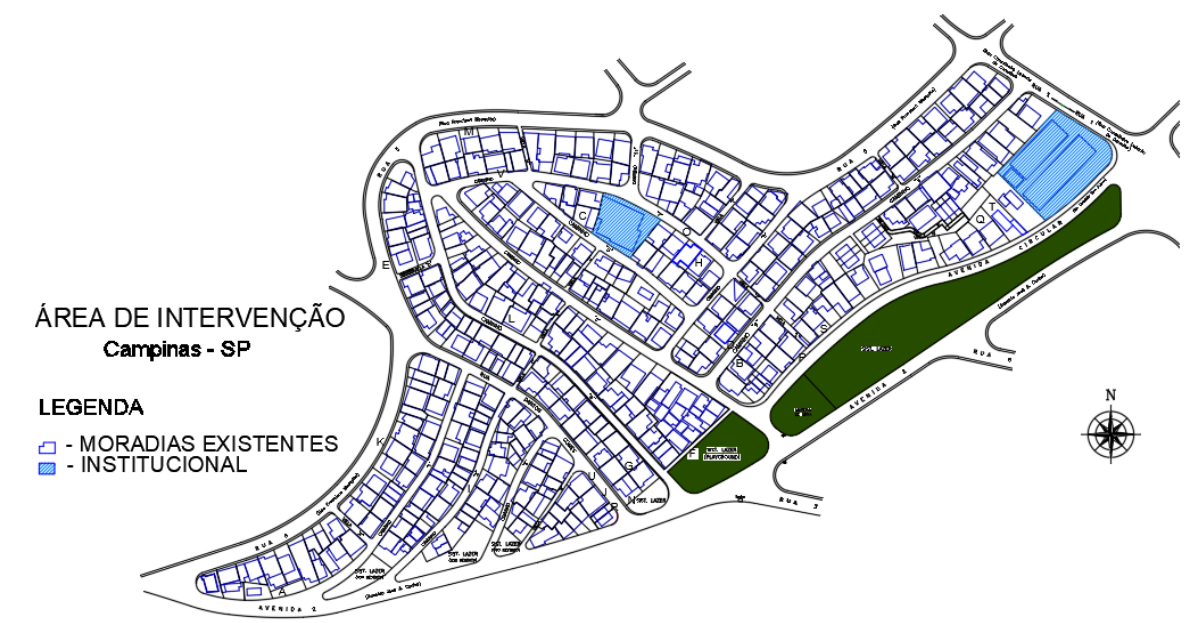

Figura 1. Área proposta pela disciplina para intervenção. Fonte: Arquivo pessoal.

A cidade, materialização do processo de urbanização e cuja concepção pode ser expressa, genericamente, pela aglomeração de pessoas com suas construções e atividades num determinado local, é uma produção humana bastante antiga. Embora sua origem não apresente data claramente definida, sua estruturação, morfologia e funcionalidade variaram consideravelmente ao longo do tempo e em diferentes espaços, ainda que inúmeros estudiosos considerem urbanização um produto da era moderna. A cidade da modernidade revela-se, isto é notório, como resultado material da superação das relações feudais pelas mercantis e capitalistas de produção no mundo ocidental (Mendonça, 2003). 
Num contexto onde o ambiente natural, paisagem intocada antes da intervenção humana, testemunha transformações tanto mais predatórias quanto mais interesse às relações de produção desperta, fica claro que a introdução de uma nova dinâmica às cidades, suplantou: "a substituição da cidade de todos pela cidade de alguns". Percebe-se que uma alta densidade mal planejada obstrui a implantação de um bom espaço urbano, extinguindo assim a vida na cidade (Gehl, 2015).

Marcada por expressivos paradoxos, a modernidade registra tanto a intensificação da degradação da natureza quanto o despertar da consciência para a intervenção racional ou planejada na alteração/construção do ambiente urbano. Uma vez constatada a condição inexorável da urbanização da humanidade, o planejamento ou ordenamento do desenvolvimento dos espaços urbanos aparece como uma necessidade de primeira ordem e, para tanto, todos os elementos componentes do meio social deveriam ser levados em consideração. Com o intuito de despertar nos alunos uma visão de reorganização desses espaços, a disciplina de Projeto IV procurou abordar nos módulos supracitados o lado contemporâneo do espaço urbano construído.

\subsubsection{Correlação de assentamento humano com a autoconstrução e o desenho urbano, na perspectiva da cidade saudável}

O sentido de "urbano" é um termo que possui um amplo significado, onde se inclui não somente as cidades, mas as vilas e bairros, enquanto "desenho", ao invés de ser uma mera interpretação estética, é muito mais a efetiva solução e/ou o processo de produção e organização dos espaços (Paoli \& Pina, 2008). As formas geográficas se alteram ou mudam de valor; e o espaço se modifica para atender às transformações da sociedade (Santos, 2012). Nenhum estudo do espaço urbano será satisfatório se não entender a segregação espacial urbana (Villaça, 2012).

Assim, o desenho urbano contemporâneo revela-se ao mesmo tempo preocupado com o desenho dos espaços enquanto entidade estética e como cenário de comportamentos e atividades. Ele está focado na diversidade de atividades que contribui na criação de espaços urbanos de sucesso e, em particular com a estrutura física que suporta essas funções e atividades propostas. Essa noção de desenho urbano pressupõe uma relação estreita entre ideias, conceitos e elementos de projeto com diretrizes e instrumentos de intervenção e de gestão do espaço coletivo.

O processo do desenho urbano, com seus conceitos e regras, deve abranger as características intrínsecas do lugar enquanto território, respeitando sua complexidade e particularidade, mantendo seu espetáculo de pessoas indo e vindo. Várias referências já reuniram e desenvolveram uma série de conceitos que juntos têm como objetivo um ambiente democrático e rico em oportunidades, através da maximização das escolhas contidas nele.

Segundo Paoli e Pina (2008), tais conceitos resumem-se em: permeabilidade, acessibilidade, legibilidade, variedade e flexibilidade e identidade e propriedade. Embora tais ideias não sejam conclusivas, são peças-chave na produção dos espaços democráticos. E precisam estar presentes desde os processos de planejamento e gestão urbana, na revitalização e inclusão dos espaços públicos nas cidades. Neste mesmo sentido, deve-se também pensar na formação dos assentamentos humanos como análise do desenho urbano e quais são os impactos climáticos originados da ocupação de sítios urbanos marcados por um alto grau de vulnerabilidade ambiental. Quando se trata de autoconstrução, as questões do ponto de vista do desempenho ambiental estão ainda mais distantes da realidade. Contudo parte desses problemas podem ser resolvidos pela aplicação dos princípios do projeto bioclimático. 0 projeto bioclimático assegura o bem-estar do ser humano dentro de condições climáticas específicas (Labaki \& Kowaltowski, 1995). Segundo Labaki \& Kowaltowski (1995), o projeto bioclimático deve ser incentivado em países como o Brasil, onde a maioria das habitações da população de baixa renda não têm possibilidade financeira de utilizar equipamento de regulagem térmica.

A partir desses conceitos inerentes ao desenho urbano, o presente trabalho destaca em especial a ocupação do espaço, de forma a integrá-lo à estrutura urbana, onde compreender a cidade em sua pluralidade é reconhecer a especificidade de cada território e seus moradores, considerando-os como cidadãos que devem ter seus direitos sociais garantidos na forma de políticas públicas afeiçoadas a seus territórios. 


\subsubsection{Análise do aspecto do solo construído ou modificado pela ação do homem}

O processo de urbanização que, ao substituir por construções e ruas pavimentadas, a cobertura vegetal natural altera o equilíbrio do microambiente. 0 espaço que, para o processo produtivo, une os homens, é o espaço que por esse mesmo processo produtivo, os separa (Santos, 2012).

O ambiente construído, seja edifício ou espaço público, possui duas etapas dentro de seu ciclo vital: a de curta duração, chamada de fase de produção, ou seja, o planejamento e a construção de um edifício ou de uma intervenção urbanística. A segunda etapa é chamada de fase de uso; a etapa de longa duração na qual o ambiente construído deve atingir sua função social, a de ser utilizado, e assim poder ser também avaliado pela sociedade e pelos seus usuários. Nesse mesmo viés, a ocupação desordenada do espaço pelo homem muitas vezes contribui para os impactos de degradação de áreas sem infraestrutura, sem equipamentos urbanos e sem posse legal do terreno, onde muitas vezes são morros e periferias, sujeitos a deslizamentos, que têm implicações diretas sobre centros urbanos e suas infraestruturas.

A integração entre uma abordagem física e humana no ambiente urbano, muitas vezes evidencia alguma incapacidade dos teóricos do espaço urbano de integrar seu trabalho numa perspectiva mais ampla do ambiente urbano, onde esse mesmo ambiente engloba componentes naturais e construídos, podendo ser abordado segundo diversos pontos de vista. Sobre abordagem que integra os problemas urbanos ao aspecto físico/humano, é importante associar-se as interações dinâmicas entre as populações e as características físicas, sociais e culturais do seu ambiente, de acordo com a Figura 2. Encarando o espaço urbano como um ecossistema, este vai interagir com os fatores bióticos, ou seja, aqueles induzidos pela existência e formação das comunidades oriundas das favelas, por exemplo, e ainda os fatores socioculturais, condicionando assim parte da população humana.

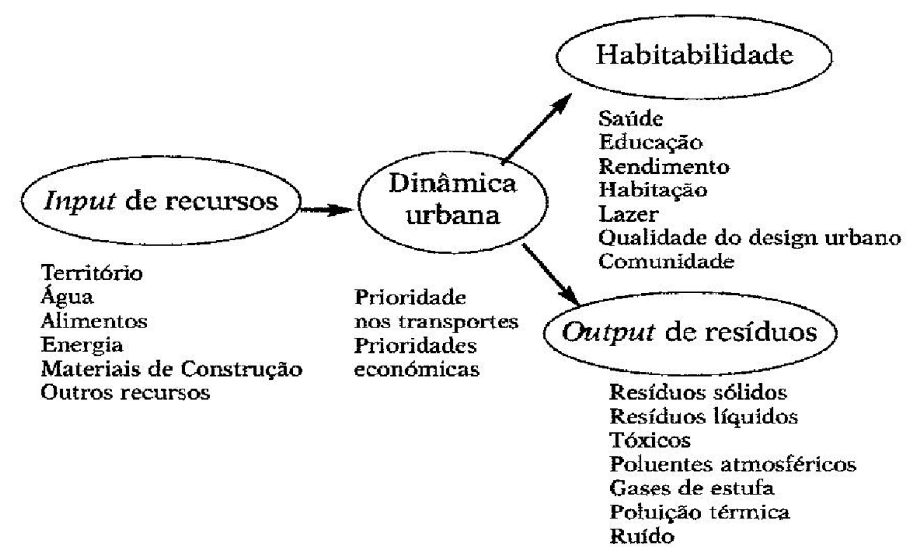

Figura 2. Modelo metabólico do espaço urbano. Fonte: Andrade, 2005.

É fato que a maioria dos assentamentos urbanos não se enquadram no modelo metabiótico do espaço urbano pela falta de recursos, pela falta da própria dinâmica urbana, onde a ocupação se estabelece de forma aleatória e imprevisível. Um exemplo disso, está na área de estudo da disciplina, onde os alunos puderam detectar a deficiência dos equipamentos públicos, infraestrutura e habitações, para assim realizarem suas propostas de projeto da HIS.

As consequências previsíveis das ocupações desordenadas do espaço urbano são muito incertas, dependendo de inserções complexas e a diferentes níveis, que podem ter resultados contraditórios e regionalmente diferenciados, contudo, com ações de mitigação, pode-se reduzir substancialmente o impacto ambiental das áreas urbanas e, consequentemente, transformar infraestruturas e padrões de consumo melhorando o meio ambiente de forma geral, de acordo com Martins e Ferreira (2010).

É pertinente neste trabalho, entender a influência da transformação do espaço sobre os assentamentos urbanos, em função de sua verticalidade, muitas vezes, desmedida e pela falta de áreas 
permeáveis suficientes para a drenagem, além de apontar os caminhos para a reabilitação dos assentamentos em geral, na perspectiva de uma cidade mais digna de viver.

\subsubsection{A lei da assistência técnica}

Em 2008 foi aprovada a Lei 11.888, Lei da Assistência Técnica. A Lei determina que famílias com renda mensal de até três salários mínimos residentes em área urbana ou rural, têm direito à assistência técnica pública gratuita para o projeto e construção de habitação de interesse social para sua própria moradia (Brasil, 2008). Essa assistência compreende ao profissional de arquitetura e urbanismo, assim como àquele de engenharia, fazer o acompanhamento na execução da obra, cujas necessidades ocorrerem em edificação, reforma, ampliação ou regularização fundiária da habitação.

Segundo nota oficial da Lei 11.888/2008, o Ministério das Cidades estruturou suas ações de política habitacional em um tripé que visa garantir ao cidadão a reforma da casa própria; a construção de unidades habitacionais destinadas, prioritariamente, à população que se encontra em áreas de risco; e a concessão gratuita da escritura de imóveis em situação irregular às famílias com renda de até três salários mínimos, por meio da regularização fundiária urbana.

Não obstante a isso, desde 2017 o CAU/BR e os CAU/DF estabeleceram o compromisso de destinar $2 \%$ de sua receita para ações e parcerias relativas à ATHIS. Em anos anteriores, o próprio CAU/BR lançou um edital, com propostas relacionadas à missão de corroborar e promover Arquitetura e Urbanismo para todos. E ainda deseja ampliar seu escopo para ações de formação dos profissionais, tendo em vista que o arquiteto e urbanista que desejar atuar nessa área, precisa se cadastrar e ficar à disposição das famílias das HIS. Quem organiza esse processo de contratação profissional é o governo local, onde existe um cadastramento das famílias, que em parceria com as entidades de Arquitetura e Urbanismo e também de Engenharia, oferece o serviço.

\subsubsection{Os aspectos sobre uma reflexão a respeito da HIS}

É preciso reconhecer que a arquitetura brasileira plasmou uma imagem, um ideário colado ao projeto de superação do subdesenvolvimento do país (Maricato, 2002). Muitos autores entendem a moradia como sinônimo de cidade, da mesma forma que a habitação na grande escala constitui a parte básica da produção urbana. Nunca é demais repetir que não é por falta de planos e nem de legislação urbanística que as cidades brasileiras crescem de modo predatório (Maricato, 2002) que segundo Villaça (2012), uma das causas fundamentais dos problemas urbanos está na ideologia dominante que acredita ser a falta de planejamento.

Na trajetória da formação dos assentamentos urbanos segundo as configurações de áreas urbanas críticas, muitas vezes torna-se difícil encontrar padrões e regras que expliquem essa realidade. A Figura 3 traz um exemplo de intervenção urbana na história abordada em diversas escalas do espaço urbano utilizando instrumentos específicos da arquitetura e do urbanismo. 0 modo de pensar uma intervenção urbanística com referenciais de projeto contribui na elaboração de espaços onde a ocupação se deu de forma aleatória e desordenada.

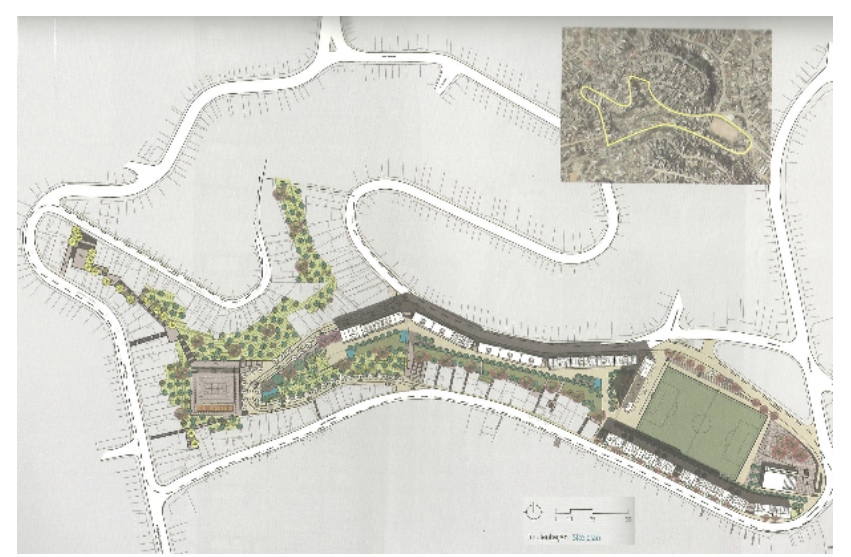

Figura 3. Viglecca \& Associados Parque Novo Santo Amaro (2009/...). Fonte: Vigliecca, 2012.

(C) Labor \& Engenho, Campinas [SP] Brasil, v.12, n.4, p.540-551, out./dez. 2018. 
No entanto, segundo Vigliecca (2012), existe uma lógica nas configurações de ocupação, resultado da transposição dos lugares de origem, da topografia e da necessidade. A Figura 4 mostra exatamente como a ocupação irregular foi inserida no meio urbano, cuja área escolhida para estudo ocupa aproximadamente $2,225 \mathrm{~km}^{2}$, com uma população de 7351 habitantes e densidade de $33 \mathrm{hab} /$ ha, segundo censo demográfico de 2010, do Instituto Brasileiro de Geografia e Estatística - IBGE, uma vez que as próprias tipologias transformaram a configuração da área. É importante entender que habitação de interesse social não pode ser um problema de quantidade, nem de custo, tão pouco de tecnologia, o objetivo final é a construção das unidades habitacionais, que consequentemente trata-se de um problema político e de projeto.

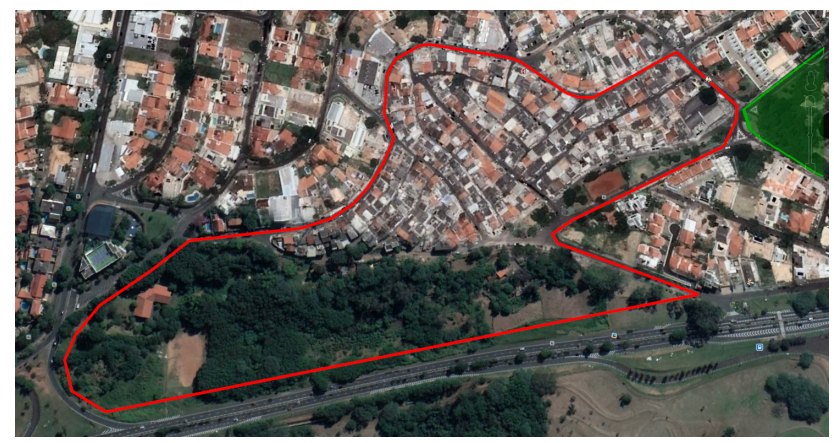

Figura 4. Área proposta de intervenção em Campinas, SP. Fonte: Google Earth, 2018.

\section{Análise de resultados}

A análise das bibliografias consultadas sobre o estudo das ocupações na cidade, sobretudo o impacto ambiental nos assentamentos urbanos e a assistência técnica aos moradores dessas ocupações, se faz através da referência sobre a evolução, as tendências e alguns desafios a serem vencidos. No caso brasileiro, a passagem do estágio de população predominantemente rural para urbana aconteceu em meados da década de 1960, tendo o processo de urbanização apresentado considerável aceleração nas décadas seguintes e estando ligado, mais diretamente, ao êxodo rural e à imigração urbano-urbano. Caracterizou-se como a urbanização do espaço, onde o processo brasileiro gerou cidades com expressiva degradação das condições de vida e do ambiente urbano. Segundo a primeira moradora do local escolhido para estudo, ali as ocupações começaram entre 1965 e 1966, na "estrada funda", caminho de entrada da vila, de onde originou a primeira rua. A falta de um projeto técnico assistido, a queda da qualidade da atmosfera urbana e os problemas humanos a eles correlatos apresentam intensificação paulatina no momento mais atual. As Figuras 5 e 6 registram locais de campanha contra as drogas, que na maioria das vezes é um fato preponderante de área e o descaso do poder público quanto a infraestrutura urbana, respectivamente.

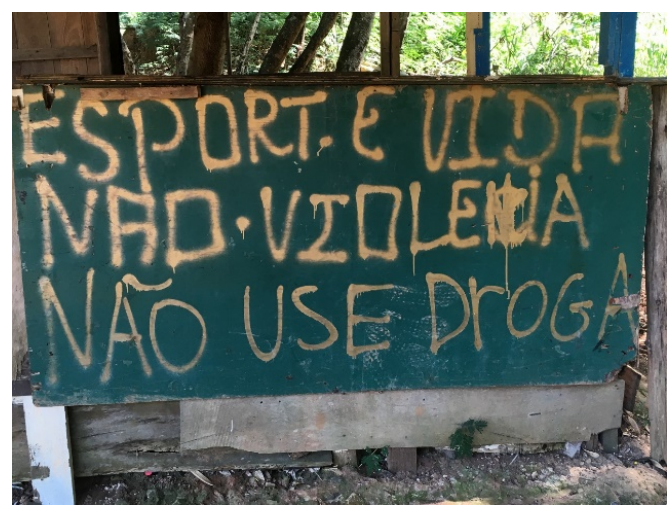

Figura 5. Mensagem localizada próxima ao campo de futebol. Fonte: Arquivo pessoal.

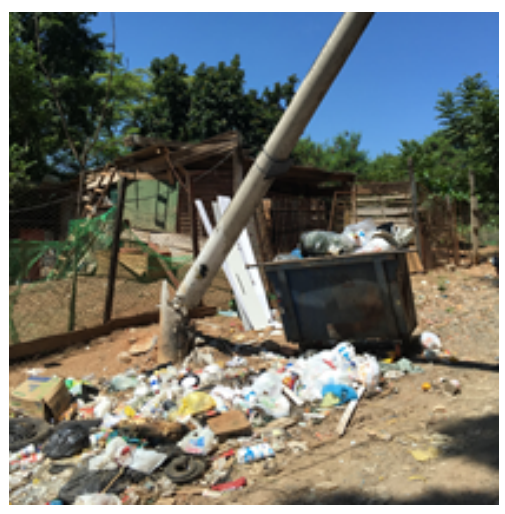

Figura 6. Falta de infraestrutura recorrente na área em questão. Fonte: Arquivo pessoal.

Segundo pesquisa feita por Labaki \& Kowaltowski (1995), existe uma incidência grande de transformações nas casas populares, seja autoconstruídas ou de conjuntos habitacionais. Na maioria das vezes, no entanto, os autoconstrutores recorrem as mudanças de espaço funcional, contudo não se preocupam, ou muitas vezes, desconhecem o conforto ambiental. Sendo assim, muitas casas 
ficam precárias das condições de conforto térmico, acústico e lumínico, tornando o ambiente propenso a baixa qualidade de vida.

Existe um grande fenômeno de "urbanização informal", e para reverter esse fenômeno deve-se pensar dentre outros aspectos, em diversificar as opções habitacionais e ofertas quanto à tipologia, nível de acabamento, tamanho das unidades, assim como o preço e a localização.

As respostas dos alunos nas propostas de projeto apresentadas como conclusão da disciplina foram plausíveis da boa arquitetura como forma de intervenção do espaço. Os discentes trouxeram tais propostas como: sustentabilidade, reciclagem, interação da população local, dos meios e entorno, uso máximo da topografia, tipologia dos apartamentos, regeneração urbana, espaços verdes e interação dos moradores com o meio, como mostra a Figura 7.

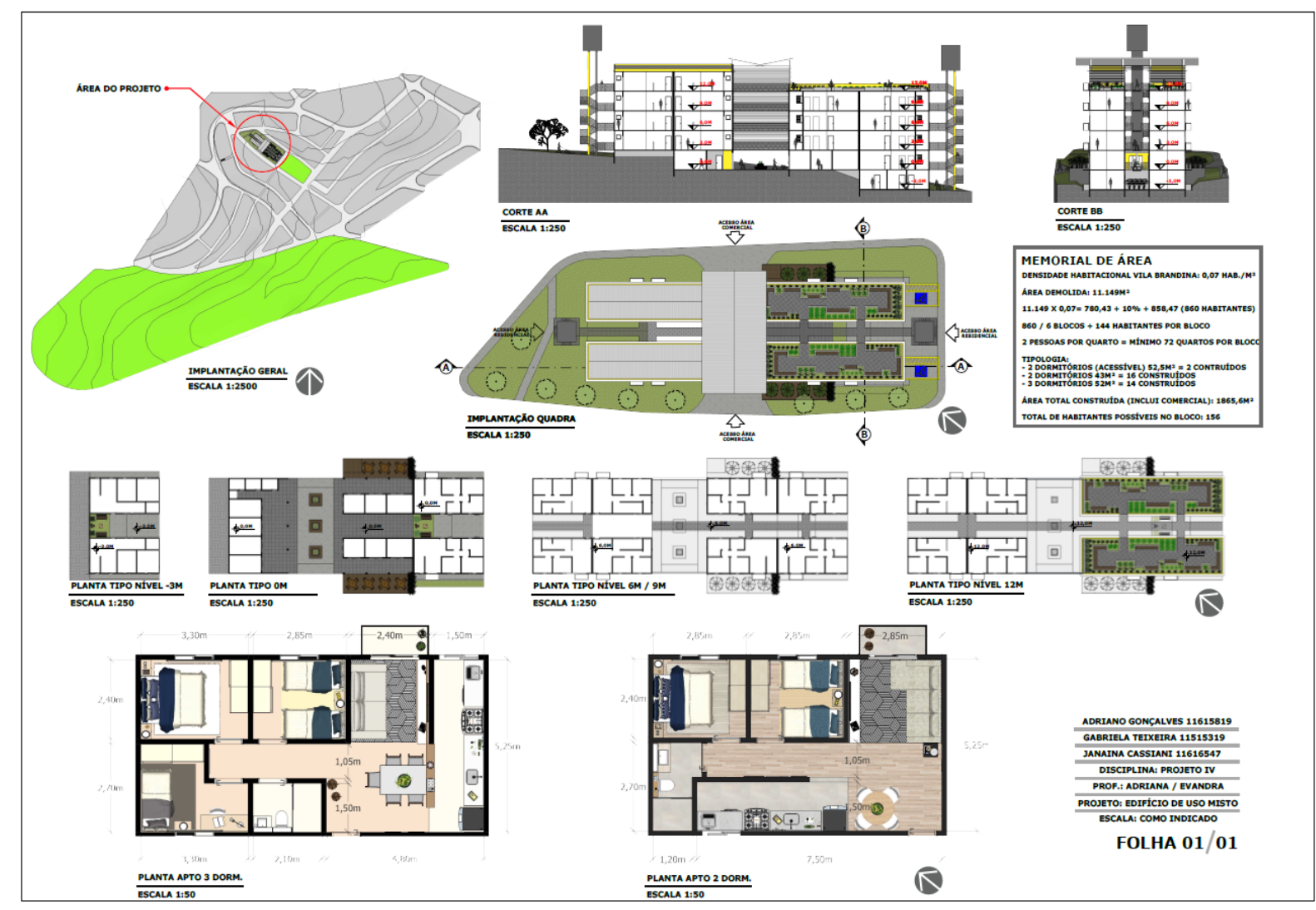

Figura 7. Prancha apresentada contendo as propostas de projeto dos alunos. Fonte: Arquivo pessoal.

A preocupação com a falta de assistência técnica à população de baixa renda, foi o principal fator a impulsionar a criação de leis que vêm contribuir positivamente aos moradores dos assentamentos urbanos, contudo com um certo retardo na execução. É bom lembrar que, parte do processo de planejamento concernente ao levantamento de diretrizes e à implementação do projeto tem ficado, genericamente, sob a responsabilidade de urbanistas com formação em outras áreas do conhecimento, quando lhe compete também a proposição de intervenção deliberada na produção de espaço urbano.

Tomando por muitos como sendo a solução racional para o equacionamento dos problemas ambientais urbanos, dentre eles a degradação da qualidade do ar, a atividade de planejamento tem sido, entretanto, bastante questionada na última década, dado que as condições de vida na cidade não apresentaram melhoria significativa, principalmente nos locais onde estão inseridos os assentamentos irregulares.

Para tanto, torna-se possível questionar, se é fato um problema de planejamento urbano, ou a cidade apresenta uma complexidade maior? Ou será que as caóticas e/ou gigantescas cidades modernas que atraem cada vez mais imigrantes tornaram-se impraticáveis para qualquer política 
de planejamento? Ou ainda, apresentaria a proposta de intervenção amparada pela assistência técnica?

Estas questões, apontam para o necessário aprofundamento das reflexões acerca dos assentamentos urbanos e de sua contribuição ao planejamento da cidade e às condições de vida, também apontando para o contexto do conforto funcional. De modo que, ao olhar para o contexto de cidade, constata-se a necessidade de mais intervenções dos assentamentos urbanos, visto que existem análise e ações de políticas públicas de governos locais que trazem em seus documentos tal iniciativa em relação à assistência técnica, contudo em muitos meios isso ainda não se aplica. $\mathrm{A}$ importância de tratar destas questões na disciplina de Projeto IV foi fundamental aos alunos numa abordagem referencial ao que se aplica a compreensão dos assentamentos urbanos e da autoconstrução dentro do espaço construído, onde a performance de uma atividade depende da interação entre o usuário e o ambiente. E quando o ambiente está propício ao bom viver, o fator preponderante é a melhor performance.

\section{Considerações finais}

A disponibilidade de recursos financeiros e humanos é fundamental para o planejamento e implementação de ações governamentais no nível local. Algumas medidas de adaptação exigem construções ou melhorias em infraestruturas urbanas que na maioria das vezes estão além da capacidade financeira dos governos locais, confirmando análise feita por Martins e Ferreira (2010).

No Brasil, cujo processo de urbanização se deu de maneira muito rápida, desigual, bem como destituído de perspectivas de planejamento, o desenvolvimento das cidades resultou na formação de espaços eivados de consideráveis disparidades socioeconômicas e de elevada degradação socioambiental. Assim sendo, a deterioração da atmosfera é, de maneira geral, apenas mais um testemunho da relação predatória entre a sociedade e a natureza. Todos esses quesitos puderam ser percebidos pelos alunos e professores durante a vista da área em questão.

Segundo França (2018), a cidade é um mosaico de centenas de territórios que foram se constituindo com características específicas, e que são resultado dos esforços coletivos e individuais daqueles que contribuíram para a construção de cada um dos bairros da cidade. Em cada um deles tem-se um palimpsesto de histórias acumuladas, que definem suas referências urbanas e seus mapas mentais da cidade (França, 2018).Na área de intervenção da disciplina percebe uma similaridade entre outras áreas cuja urbanização ocorreu da mesma forma. Onde há um assentamento urbano sempre há, como França (2018) já dizia, um campo de futebol construído por moradores, uma pequena igreja, a casa de cada um que vai sendo ampliada à medida das possibilidades financeiras da família e, claro, os locais de encontro que são os pequenos e criativos espaços públicos implantados nos remanescentes da ocupação irregular.

Parece necessário encontrar novas estratégicas para uma efetiva sensibilização dos homens encarregados das tomadas de decisão nas esferas estatais individualmente, e também nas instituições de caráter supra e transnacional, para a importância dos assentamentos urbanos e autoconstrução, na compreensão do espaço e sua interação com a sociedade. A humanidade parece já ter ido longe demais negligenciando seus impactos sobre a natureza e os impactos desta sobre a sociedade. No contexto do movimento internacional de conscientização da situação da humanidade quanto ao seu bem-estar tem sido dada relevância à promoção da saúde, o que inclui meio ambiente favoráveis e políticas públicas mais condizentes e integradoras (Franco Netto, Drumond \& Vasconcelos, 2010).

Recomenda-se que os estados de governo avaliem, as consequências das ocupações irregulares nas cidades, de modo a que não sejam iniciadas urbanizações inadequadas e que as adaptações a novas condições habitacionais possam ser incorporadas e assistidas no processo de ordenamento do território.

A aplicação da assistência técnica aos assentamentos urbanos no planejamento das cidades é um objetivo apontado por quase todos os autores. A construção da falta de aplicação é também muito frequente. É, em geral, referida a adequação ao projeto dos modelos urbanos e arquitetô- 
nicos tradicionais, em contraste com a prática cultural do desenho urbano, caracterizado pela pouca ou nenhuma atenção dada as condições humanas. Contudo, muitas das apreciações sobre a adequação projetual dos modelos tradicionais são vagas e baseadas em observações isoladas, qualitativas e de senso comum.

\section{Referências}

Andrade, H. (2005) O clima urbano - natureza, escalas de análise e aplicabilidade. Finisterra, XL, 80, pp. 67-91.

Brasil (2008). Lei n.o 11.888 de 24 de dezembro de 2008. Assegura às famílias de baixa renda assistência técnica pública e gratuita para o projeto e a construção de habitação de interesse social e altera a Lei n.ำ11.124, de 16 de junho de 2005. Brasília, DF.

Braga, R. (2012). Mudanças climáticas e planejamento urbano: uma análise do Estatuto da Cidade. In: VI Encontro Nacional da Anppas, Belém, PA.

França, E. (2018). Os planejadores urbanos e a periferia. Estadão, Esquina, Planejamento, São Paulo.

Franco Netto, G., Drumond, I., \& Vasconcelos, N. (2010).Meio ambiente e promoção da saúde: aspectos essenciais para a elaboração das políticas públicas. In: A.M.G. Sperandio, D.G. Machin, \& M.A.B. Fortunato (orgs.). Políticas integradas em rede e a construção de espaços saudáveis: boas práticas para a iniciativa do rostos, vozes e lugares. Brasília: Organização Pan-Americana de Saúde.

Gehl, J. (2015). Cidades para pessoas. 3 ed. São Paulo: Perspectiva.

Instituto Brasileiro de Geografia e EstatíStica - IBGE (2011). Base de informações do Censo Demográfico 2010: Resultados do Universo por setor censitário. Rio de Janeiro.

Labaki, L. C., \& Kowaltowski, Doris C C K. (1995) Projetos padrão de conjuntos habitacionais de Campinas e seu conforto térmico: análise de possíveis melhorias. In: Encontro Nacional de Tecnologia do Ambiente Construído - ENTAC 95, 1995, Rio de Janeiro, RJ. ENTAC 95, Anais. Rio de Janeiro, RJ: ANTAC, 2, pp. 593-598.

Labaki, L. C., \& Kowaltowski, Doris C C K. (1998). Bioclimatic and Vernacular Design in Urban Settlements of Brazil. Building and Environment, 33(1), pp. 63-77.

Maricato, E. (2002). As ideias fora do lugar e o lugar fora das ideias: planejamento urbano. In: Arantes, O.; Vainer, C.; Maricato, E. A cidade do pensamento único: desmanchando consensos. 3. ed. Petrópolis, RJ: Vozes.

Martins, R. D., \& Ferreira, L. C. (2010) Oportunidades e barreiras para políticas locais e subnacionais de enfrentamentos das mudanças climáticas em áreas urbanas: evidências de diferentes contextos. Ambiente \& Sociedade, Campinas, 13(2), pp. 223-242, jul-dez.

Mendonça, F., \& Monteiro, C. A. F. (2003) Clima urbano. São Paulo: Contexto, 192p.

Moysés, S. T., Krempel, M. C., \& Moysés, S. J. (2010) Intersetorialidade: estratégia para a construção de uma cidade saudável. A experiência de Curitiba. In: A.M.G. Sperandio, D.G. Machin, \& M.A.B. Fortunato (orgs.). Políticas integradas em rede e a construção de espaços saudáveis: boas práticas para a iniciativa do rostos, vozes e lugares. Brasília: Organização Pan-Americana de Saúde.

Paoli, D. D., \& Pina, S. A. M. G. (2008). Desenho Urbano nas áreas habitacionais: uma metodologia de análise conceitual. In: $7^{\circ}$. Seminário Internacional Espaço Sustentável — Inovações em Edifícios e Cidades. NUTAU 2008, FUPAM, FAU-USP, 2008. São Paulo, SP, Brasil.

Pina, S. A. M. G. et al. (2002). Ação e cooperação na questão da habitação social em área de interesse ambiental. In: IX Encontro Nacional de Tecnologia do Ambiente Construído - ENTAC 2002, Foz do Iguaçu, PR, Anais, 7 - 10 maio 2002. pp. 799-808. 
Romero, M. A. B. (2000). Princípios bioclimáticos para o desenho urbano. São Paulo: Projeto Editores Associados Ltda., 128 p.

Rosa, A. A. C. (2017) Conforto ambiental em espaços urbanos abertos: sua correlação com o planejamento de cidades. ISSN 1679-8902 Revista Intellectus. Jaguariúna, 1(38), pp. 45-56.

Saldiva, P. (2018). Vida urbana e saúde: os desafios dos habitantes das metrópoles. São Paulo: Contexto.

Santos, M. (2012). Pensando o espaço do homem. 5a. ed. São Paulo: Edusp.

Vigliecca, H. (2012). Áreas urbanas críticas. Revista Monolito. São Paulo, 7, pp. 92-95, fev/mar. Bimestral. ISSN 2179-748X.

Villaça, F. (2012). Reflexões sobre as cidades brasileiras. São Paulo: Studio Nobel. 